\title{
Paragliding Ground Handling Training Model With a Combination of Belayer, Ancoring and Simple Towing in Above Normal Wind Condition
}

\author{
Sahri $^{1}$, Sugiharto ${ }^{2}$, Nanang Indardi ${ }^{3}$, Nur Amin ${ }^{4}$, Aristiyanto ${ }^{5}$, Alya Ega Suciana ${ }^{6}$, Wahyu \\ indra Wijaya ${ }^{7}$ \\ \{sahri@mail.unnes.ac.id ${ }^{1}$, sugiharto.ikor@mail.unnes.ac.id ${ }^{2}$, nanangindardi@mail.unnes.ac.id ${ }^{3}$ \}
}

Universitas Negeri Semarang, Semarang, Indonesia ${ }^{1,2,3}$

\begin{abstract}
This research to improve students' skills Ground Handling abilities in Paragliding Subjects using the belayer, anchoring, and simple towing methods. Respondents are 18 students of the Sport Science Department who took Paragliding courses. Inclusion criteria were healthy, never had a heart attack. Respondents with height phobia were divided into 3 treatment groups and 1 control group. This research was conducted in two cycles, each cycle consists of two meetings. The results of percentage classical completeness in cycle 1 of $48.2 \%$ increase to $73.2 \%$ in cycle 2 . The initial stage 4 groups that have the ability to master ground handling material in wind conditions above normal with mastery between $6 \%-7 \%$, in the middle stage there was the belayer group with a result of $22 \%$, the ancoring group $19 \%$. and the simple towing group $21 \%$, but at the end of the session the results achieved had a significant difference, namely $65 \%$ for the belayer group, $52 \%$ for the ancoring group, while the simple towing group reached $73 \%$ capable, this result ignores gusty fluctuations. Hot and humid weather conditions that can change from time to time when learning data are documented.
\end{abstract}

Keywords: Paragliding, ground handling, ground handling method.

\section{Introduction}

The skill of controlling a parachute on a flat field in Paragliding related to the condition of students in lectures is something that needs to be evaluated continuously, so that the final product of the lecture will get maximum results. The orientation of the skill performance applied by students in the field is evaluated by the effectiveness of the work performance, which is defined as the result of the Paragliding course lecture. The ability to perform in preparation for the flat field before flying, ground handling, during the paragliding flight stage is prioritized to achieve real paragliding performance. In countries that have advanced in paragliding as a sport and tourism it has been shown that a decrease in a practitioner of paragliding during flight is highly correlated with early performance and better ground handling abilities [1], [2]. Therefore, a paragliding student needs to direct mastery of this initial stage, to produce maximum performance during the actual flight later. Paragliding lectures with stages and using the help of tools, including special strategies in Paragliding education, are often used by lecturers who teach courses to increase acceleration or acceleration in learning [2]. The lecture method by adding a step of instruction in standard procedures in lectures includes wearing additional ground handling safety and security devices [2], [3]. Ground Handling with the help of belayer, 
anchoring, and simple towing has a positive influence on students and is very effective in improving early flight performance [2], [3], [4]. The lecture stimulus depends primarily on the clarity of speech and the emphasis of the words that come from the lecturer to the students. Clarity of instruction and systematics or sequences of orders must be considered because they both affect the amount of attention and achievement of lecture results [5], [6].

Previous studies of instruction in learning with an emphasis on systematics and clear sequences of orders show that the utterance of every word that comes out of the lecturer can cause changes that may reduce the quality of understanding of each form of command in lectures [4]. However, considerable stress in instruction may be required to provide sufficient learning stimulus to increase command absorption and concentration development during the flight preparation phase [5], [7].

Another related report is that the relationship between paragliding flight readiness and the relationship of emergency during flight has been examined. The main variables of this relationship are ground handling ability, self-control ability and potential leg injury, which corresponds to the maximum mechanical ability of the lower limb to show good flight performance. These psychological and physiological parameters are influenced by body flexibility, muscle and nerve activity, and ligament and muscle joint configuration. Therefore, ground handling skills using belayer, anchoring, and simple towing methods are important. Greater understanding of ground handling and take off in an integrated manner may also benefit students and lecturers. Based on observations of researchers in the field (in Indonesia), it was found that the instructor or assistant instructor of the paragliding club in learning activities is monotonous, instructor-centered, only uses a drill approach, and only emphasizes motor mastery while other aspects are neglected such as intellectual, mental and values. other aerospace. As a result of this, club members tend to be indifferent, lack motivation to learn and practice, feel bored, and lack creativity. Supposedly, it is necessary to plan for paragliding learning and training that is goal-oriented and tries to adapt to the physical and psychological conditions of club members so that they carry out learning and training activities optimally. Another experience from a field study about ground handling and drill takeoff-landing on a broad hill (without any obstacles or obstructions) can be an ideal effort to be used as a place for student learning. However, such an ideal system is very expensive to implement and complicated in Paragliding Sports courses in the Semarang area, where the university is located. Furthermore, because ground handling capability is considered important, it is necessary to understand this effect not only at the first second but also at the end of the actual flight stage. As far as the researchers' knowledge, no study has analyzed ground handling methods with the help of belayer, anchoring, and simple towing.

As a way of solving and overcoming the problems of learning spaces and training fields that have to move around in relation to the wind speed which always changes in each season, it is overcome with belayer, anchoring, and simple towing methods for students in flat terrain conditions and winds above normal. The belayer, anchoring, and simple towing methods are used as teaching tools and practical exercises aimed at deepening ground handling techniques that have been carried out normally in normal winds.

In the current era of science and technology, innovations in tactical methods are no longer carried out by promoting the laminar and gentle wind, which is common in lectures until now. Belayer, anchoring, and simple towing methods are expected to facilitate learning and drilling more frequently so that students can perform and master basic flying techniques faster, but have the potential to reduce high costs for moving lectures. 
Based on the description, the authors formulate existing boundaries to be used as a starting point for the discussion in this paper, namely the belayer method, anchoring, and simple towing on paragliding ground handling.

Indonesia is a country with a lot of hills and volcanoes, so the sport of paragliding has grown better, but among this sport little research is related to it, and little is known about the specific behavior associated with it. Adventure recreational sports, mainly practiced on the grounds of tourism, are enjoyed throughout the world, with several studies examining the behavior of adventure recreation users. Most of the overseas researchers and scientists took the adventure model of Ewert and Hollenhorst [8] in their analysis of the data evaluating these activities, while Schuett found the independent variable "activity participation rate" that did not have an appropriate measurement scale. He suggests replacing it with "more lasting engagement" to ascertain how tourists find their interests and develop their skills. There are similar studies, only Li and $\mathrm{Ou}$ [9] examined personal or professional background, recreation motivation, and preferences for environmental characteristics of paragliding consumers. Ho, Chung, and Chen used Ewert and Hollenhorst's model to ensure that long-lasting involvement of paragliding practitioners means higher frequency of participation, skill levels and risk awareness [10].

Previous field studies have focused on correlations, differences, and/or preferences for environmental attributes. Several studies have explored demographic and behavioral differences [11] or analyzed the impact of regional development paragraphs on regional economies [12]. Others conducted engagement analyzes with regard to sports injuries [13] and psychological impact. Apart from participatory adventure recreation behavior, many concerns focus on motivation [14].

Few studies have examined the importance of flight preparation especially Ground Handling in the overall flight effort, empirical research has explored less than participation in these activities. Pomfret suggests that future study analyzes of engagement impact participants in a profound way. In addition to completing the gap in theoretical studies, it can also be a basis for developing paragliding activities more broadly in Indonesia [15].

\section{Method}

Based on the narrative described above, in a practical way, the steps of the research carried out are as follows: (1) Conducting preliminary research in the form of a survey of lecturer performance in lecture management; (2) Compiling the initial model design of the learning model, starting to design the planning, implementation, and evaluation of learning; and (3) Making observations in two stages. The sample consisted of 18 male and female students with certain characteristics, healthy with a doctor's certificate, had never had a heart attack and were not afraid of heights. Data collection techniques used in this study were observation (observation), interviews, documents and questionnaires. Observations were made at each stage of the research, starting from the pre-survey stage, 1 st observation stage to 2 nd observation stage which was more typical. Interviews and questionnaires were used at the pre-survey stage, before the assessment stage. Document analysis is used to collect data, especially in preliminary studies, namely to answer research questions related to planning and implementing Paragliding sports lectures that have been implemented by lecturers.

The next stage, consisting of determining the standard procedure for the implementation of the paragliding lecture / learning program using the belayer, anchoring, and simple towing 
methods, which includes 1) observation and field orientation / ground handling field (soil conditions, grevel, tartan, chalk line, grass. , drainage channels, soil and environmental moisture conditions, wind direction, wind speed, wind type, and sun heat);2) preparation of supporting resources and equipment for lectures / learning (personal, moral, individual and administrative tools); 3) carrying out the opening session of lecture preparation (brainstorming, warming up, quiz, recalling apparatus and daily procedures); 4) the core of the lecture (according to the research instrument phase three protocol which is not written in this article); 5) closing the lecture (closing session); 6) analyzing the achievement of lecture objectives and the absorption of lecture material; 7) determine the points of conclusion. Additional notes, that in order to initiate the protocol using belayer, anchoring, and simple towing methods in lectures, reobservation and re-orientation of the lecture environment are carried out. This protocol includes 1) filling in a point to point checklist for inspecting the launching equipment and units to ensure that they are in good condition; 2) observing with focus every movement of lecture participants who carry out ground handling; 3) sensitive to every response made by the paragliding unit (person and glider unit) when forming kites (kiting); 9) resetting the ground handling protocol to normal.

These classroom action research steps aim to develop new abilities and skills, new approaches or a new product of knowledge to solve problems with real-time direct application in the field, in line with Arikunto's [16] opinion that: "classroom action research is a observation of learning activities in the form of an action that is deliberately raised and occurs in a class together". Furthermore, this research is carried out in a cycle, where one cycle itself consists of 14 days or 2 weeks starting with the first cycle, if there is no significant change in the first cycle then it can be continued to the next cycle until the target of material absorption in lectures can be achieved properly. By using 2 cycles to achieve the classical absorption criteria. This study uses a model according to Suharsimi Arikunto's view that classroom action research has four stages, namely the planning stage, the implementation stage, the observation and reflection stage [16]. Stage 1 (first) is called pre-research, measuring ground handling skills with ground handling performance in winds above normal, to determine the ability of ground handling performance in winds above normal and the results of these tests will be used as guidelines for researchers to conduct research using the belayer method. , anchoring, and simple towing.

\section{Result and Discussion}

The next stage is called the research implementation stage, which consists of cycle I (first), for two weeks students face ground handling lectures with winds above normal, followed by data collection on ground handling skills tests. The test results are announced immediately at the end of the score taking, followed by a discussion of the results of the skills test and there is an opportunity for questions and answers about the lectures that have been carried out. Lecturers are involved in discussion and evaluation of lectures. Observations were made two weeks after the students received a lecture on gorund handling with winds above normal, as a researcher who was annoyed by a lecturer, the next task was to collect data to determine changes in student skill abilities. Reflection is carried out on the assessment results data during the lecture process that has taken place in Cycle I, the results are to determine the ability of cycle I and as a guideline that is conveyed to students. If it is found, it is not according to the lecture target, then the next cycle is carried out, namely Cycle II. In Cycle II all protocols were carried out in accordance with Cycle I, Cycle II was carried out for two weeks and then the student ability data were taken. 
At the end of the test, the test result value is read, which is used as a benchmark to determine the increase in ability after Cycle II is carried out, at this stage a reflection of the results is also carried out.

There are several notes, namely 1) in the field observation and orientation activities or ground handling sites, it is noted that the dry soil conditions are ideal for learning / lecturing paragliding, the dewy grass tends to be wet until around 9 am so the new field is ready and ideal for lectures at that time, the channel clean drainage from standing water is safe for malorientation that leads to trenches, less than ideal soil and environmental conditions in the hours before 9 am, wind direction, wind speed, wind type, ideal sun heat; 2) the preparation of supporting resources is supported by 3 assistants from senior paragliding activists, while 5 units of lecture / learning equipment and individual equipment are available and are classified as inadequate both in quality and quantity, however administratively they are completely available ; 3) carry out the opening session (opening session) of lecture preparation consisting of brainstorming, warming up, quizzes, recalling apparatus and daily procedures carried out by the lecturer correctly and systematically but the students' attention is less focused; 4) at the core of the lecture (according to the stage three research instrument protocol which is not written in this article) was carried out ineffectively because it was constrained by the number of gliders and the lecture area used was quite wide while the lecturers were without loudspeakers; 5) closing the lecture at the closing session was recorded quite effectively with questions and answers related to the material, however, the shady situation under the tree made some students less focused. There are observation points as follows: 1) the preparation stage for performing / showing religious attitudes and behavior before starting a series of activities; 2) carry out selfsecurity measures in a convincing manner, which include: -Using a helmet to glue the safety rope with a "click" sound; tidy up shoes to clothing parts thoroughly; stretch the glider carefully, with an efficient and steady motion; perform a careful physical inspection of the glider, line, both raisers and toggle; wearing the harness by making sure the chest strap, leg strap, main strap are connected to the connector until you hear a "click" sound; ensure sure performance of the raiser interconnection movement with the harness; carry out the environmental orientation of launching ground including wind direction and field punctuation in the form of wind shook and crepe paper strands; (As a note, that this component was carried out steadily by the lecturers, but less steadily by almost all students at the beginning of the study). In the next stage, Kiting with the following components of observation: -participants perform / show a serious / steady attitude and behavior, starting the glider lift with steps and movements that efficiently adjust the glider to form the glider wall with the glider's nostrils facing upward relatively steadily and convincingly; - Carry out the glider control steps while gradually moving up, showing a confident and focused attitude towards the glider and the body position of the glider in a convincing manner, within a determined period of time (gradually) which includes: Ensuring maintaining the stance and positioning of the footrests when the glider moves towards above and form a canopy; Shows a calm and flexible attitude and movement towards each glider's movement adapting to the movement of the wind; Keeping the line tension still in position forms a canopy unit against the body, within the specified time; Adjusting the lower and re-tensing of the glider line unit followed by a calm and reasonable reversal of the body. Repeating point 4) steadily according to the specified stages; Lower the glider calmly and steadily until it reshapes the glider's wall on the ground while keeping the line. 


\section{Conclusion}

Based on the results above, it can be concluded that the ability to construct new knowledge; while the implementation of this learning model is the implementation of the lecture plan carried out to jointly study the determined competencies, which are formulated in the paragliding field lecture scenario which includes the main activities of carrying out the opening activity ( opening session) class preparation (brainstorming, warming up, quizzes, recalling apparatus and daily procedures); 4) the core of the lecture; 5) closing the lecture (closing session). The evaluation carried out includes the evaluation of the process and results. Process evaluation serves to obtain information about capacity building. Evaluation of the results is functioned to obtain information about the student's ability to master lecture material. The results of action research in this lecture are the first that the belayer, anchoring, and simple towing method can improve learning outcomes of Ground Handling. This is evidenced by an increase in the average from cycle 1 to cycle 2 with the percentage of classical completeness in cycle 1 of $48.2 \%$ increasing to $73.2 \%$ in cycle 2 , with details that can be reported is that at the initial stage 4 groups have the ability to master ground handling material in wind conditions above normal with mastery of achievement between $6 \%-7 \%$, in the middle stage session there were differences, namely the belayer group with $22 \%$ yield, and $19 \%$ ancoring group. and the simple towing group $21 \%$, but at the end of the session the results achieved had a significant difference, namely $65 \%$ for the beleyer group, $52 \%$ for the ancoring group, while the simple towing group achieved $73 \%$ success, this result ignores gusty fluctuations. hot weather conditions and humidity that can change from time to time when the learning outcome assessment data is documented. It is hoped that it can increase the effectiveness of Paragliding lectures at the University.

\section{References}

[1] H. M. Li and H. S. Ou. Relationships between participants, characteristics of Para-Glider and Preferences of Environmental attributes. in 4thLeisure, Recreation, and Tourism Processing: Leisure Theory and Recreation Behavior, Taipei, The Outdoor Recreation Association, 2002, pp. 263-270.

[2] M. C. Hsiao and T. H. Yu. Paragliding Adventure Recreation Consumers' Activity Motivation, Enduring Involvement and Their Involved Behavior. The Journal of International Management Studies. 2012; 7(2).

[3] P.d. Jairo Antônio and T. Guilherme. Risk Perception for Paragliding Practitioners. International Journal of Sports Science.2012; 2(2): 6-10.

[4] H. L. Ho, W. C. Chung and T. H. Chen. Applying adventure model for behavior of participators in paragliding. Tourism Research Bulletin. 2005; 11 (4): 275-300.

[5] R. M. Fluker and W. L. Turner, Needs, motivations and expectations of a commercial whitewater rafting experience. Journal of Travel Research. 2000; 38: 380-389.

[6] A. Ewert and S. Hollenhorst, Adventure recreation and its implications for wilderness. International Journal of Wilderness. 1997; 3 (2): 21-26.

[7] Gall, R. . W. Borg and Meredith, Fouth Edition Research An Introduction., USA: Logman, 1983

[8] C. Schott, Selling adventure tourism: A distribution channels perspective. International Journal of Tourism Research. 2007; 9: 257-274.

[9] A. M. Schuett. Testing the adventure model for outdoor adventure recreation participation. Unpublished doctoral dissertation University of Illinois, Urbana- Champaign., 1991

[10] N. McIntyre and J. Pigram. Recreation specialization reexamined: The case of vehicle-based campers. Leisure Sciences. 1992; 14 (1): 3-15.

[11] P. Oliveira and T. P. Pereira. Who values what in a tourism destination? The case of Madeira Island. Tourism Economic. 2008; 14 (1): 155-168. 
[12] A. C. Costa and L. Chalip. Adventure sport tourism in rural revitalization: An ethnographic evaluation. European Sport Management Quarterly. 2005; 5(3): 257-279.

[13] T. Bentley, J. S. Page and A. K. Macky. Adventure tourism and adventure sports injury: The New Zealand experience. Applied Ergonomics. 2006; 38 (6): 791-796.

[14] C. Willing. A phenomenological investigation of the experience of taking part in extreme sports. Journal of Health Psychology. 2008; 13 (5): 690-702.

[15] G. Pomfret. Mountaineering adventure tourists: a conceptual framework for Research. Tourism Management. 2006; 27: 113-123.

[16] Arikunto Suharsimi. Prosedur Penelitian Suatu Pendekatan Praktik. Jakarta: PT Rineka Cipta. 2014. 